\title{
DESENVOLVIMENTO DE DISPOSITIVO CASEIRO PARA DESSALINIZAÇÃO DE ÁGUA SALOBRA A PARTIR DE SEMENTES DE UMBU (Spondias tuberosa Arruda Câmara)
}

Joilma da S. Menezes, Vânia P. Campos* e Tadeu A. de C. Costa

Departamento de Química Analítica, Instituto de Química, Universidade Federal da Bahia, Campus Univ. de Ondina, s/n, 40170-290 Salvador - BA, Brasil

Recebido em 20/1/11; aceito em 20/7/11; publicado na web em 2/9/11

\begin{abstract}
DEVELOPMENT OF A HOMEMADE DEVICE FOR DESALINATION OF BRACKISH WATER USING UMBU SEEDS (Spondias tuberosa Arruda Câmara). The goal of this work was to develop a homemade device to desalinate brackish water, using biological material like seeds from different plant species of the semi arid regions. Umbu seeds (Spondias tuberosa Arruda Câmara) were found to be the most appropriate material, removing a higher quantity of salt from the water compared to the other tested materials. The salt content in $1 \mathrm{~L}$ of brackish water typical of the region can be removed with only $1 \mathrm{~g}$ of the material, if the water is heated to $50{ }^{\circ} \mathrm{C}$ and it may also lower the water hardness, achieving drinking water standards.
\end{abstract}

Keywords: desalinization; brackish water; semi arid region.

\section{INTRODUÇÃO}

O volume estimado de água no planeta é de 1,4 bilhões de $\mathrm{km}^{3}$ e cobre cerca de $71 \%$ da superfície da Terra. Apesar disso, muitas localidades ainda não têm acesso a quantidades de água com características de potabilidade adequadas às necessidades do consumo humano. ${ }^{1}$ Do volume total de água existente na Terra cerca de $97 \%$ constituem as águas dos oceanos, restando, portanto, apenas $3 \%$ de água doce no planeta. Desse percentual de água doce, $2 / 3$ estão nas calotas polares e nas geleiras e apenas $1 / 3$ do volume inicial pode ser utilizado ou consumido pela população mundial. ${ }^{2}$

Segundo a Organização Mundial de Saúde, OMS, o Brasil é um país privilegiado em termos de recursos hídricos, pois possui cerca de $12 \%$ de toda a água da superfície do planeta. ${ }^{3}$ No entanto, a distribuição dessa água no território nacional não é ideal, uma vez que $72 \%$ desses $12 \%$ se localizam na região norte, onde vive apenas cerca de $7 \%$ da população e onde a capacidade de oferta média de água por habitante nos rios está acima de $20.000 \mathrm{~m}^{3} \mathrm{hab}^{-1} \mathrm{a}^{-1}$. Por outro lado, o Nordeste brasileiro, com $28 \%$ da população do país, possui apenas $3 \%$ daquela oferta, $2 / 3$ dos quais localizados na Bacia do Rio São Francisco. A vazão média de água por habitante nos rios nordestinos é de $4.300 \mathrm{~m}^{3}$ hab $^{-1} \mathrm{a}^{-1}$. O estado da Bahia, que inclui o Rio São Francisco como seu maior aliado, cortando o território baiano de sul a norte, tem capacidade para atender cerca de $3 \mathrm{mil} \mathrm{m}^{3} \mathrm{hab}^{-1} \mathrm{a}^{-1}{ }^{4}$

O estigma da escassez da água no Nordeste, já que existe uma oferta de água doce, está caracterizado pelo fato de $80 \%$ das descargas dos rios ocorrerem nos setores ocupados por $5 \%$ da população, enquanto os $20 \%$ restantes abastecem $95 \%$ do contingente. ${ }^{5}$ Do subsolo da região, sem risco de esgotamento dos mananciais, poderiam ser extraídos pelo menos 19,5 bilhões de $\mathrm{m}^{3}$ de água por ano (40 vezes o volume explorado hoje). O uso dessa água, porém, é limitado por um problema típico da água da região nordestina: o teor de sal. Grande parte da área está situada sobre rochas cristalinas e o contato no subsolo por longo tempo entre a água e esse tipo de rocha favorece a sua salinização. ${ }^{6-7}$

Para enfrentar a escassez de água de boa qualidade no Nordeste nas últimas décadas vem-se usando a dessalinização de águas salobras, visando possibilitar condições de usos mais nobres. A dessali-

*e-mail: vaniaroc@ufba.br nização de águas, no entanto, exige normalmente alto investimento e recursos tecnológicos complexos.

O método mais usado para a dessalinização de água no Nordeste se baseia no processo de osmose inversa. Entretanto, a osmose inversa implica na geração de rejeito, uma água residuária do processo, com alta concentração iônica. O rendimento teórico é de aproximadamente $75 \%$, ou seja, cerca de $25 \%$ da água bruta se transforma em rejeito salino. ${ }^{8-10}$ Esses efluentes, quando não bem gerenciados podem gerar problemas ambientais maiores como, por exemplo, a salinização do solo e consequente infertilidade agrícola. Por outro lado, os equipamentos utilizados para a dessalinização têm vida útil reduzida e sem a manutenção devida acabam abandonados, fazendo com que os antigos problemas voltem a aparecer., ${ }^{9,10}$

Uma solução simples e eficiente para as comunidades do Semiárido é sugerida neste trabalho, com a dessalinização das águas salobras pelo contato com materiais biológicos como sementes, que adsorvem sais, reduzindo a salinidade da água, mesmo que sua aplicação seja mais adequada para pequenas quantidades, suficientes para a dessedentação humana. Assim, este trabalho teve como objetivo desenvolver um dispositivo caseiro para dessalinização de água salobra, em pequenas quantidades, suficientes para uso familiar em dessedentação humana, utilizando como adsorvente de sais material biológico, como espécies de sementes de plantas típicas ou bem adaptáveis em regiões semiáridas.

\section{PARTE EXPERIMETAL}

Para os experimentos utilizou-se água de salinidade $0,7 \%$ (baixa salobridade de ocorrência frequente no semiárido baiano). ${ }^{11}$ Após o contato da água salobra com o material biológico, o sódio remanescente na água foi analisado por fotometria de chama (Micronal, mod. B462).

Dez tipos diferentes de materiais foram estudados: sementes de amêndoa - Terminalia Catappa L., umbu - Spondias tuberosa Arruda Câmara, moringa - Moringa oleifera Lam, mulungu - Erythrina verna Veloso, umburana - Amburana cearensis (Freire Allemão) A.C. Smithera, bucha vegetal - Luffa cylindricall (L.) M. Roem, algaroba - Prosopis juliflora (SW.) D.C., abóbora - Cucúrbita pepo L., girassol - Helianthus annuus L., além de mesocarpo e endocarpo de coco - Cocos nucifera $L$. 
Considerando que o $\mathrm{NaCl}$ é normalmente o principal sal responsável pela salinidade da água, foi possível basear a metodologia empregada, com relação ao estudo da sorção de sais pelos diferentes materiais biológicos, através da análise de sódio na água antes e após contato/sorção de sais pelo material.

Água com salinidade de $0,7 \%$ o foi preparada para simular a água salobra mais frequentemente encontrada no semiárido baiano, pesando-se $0,724 \mathrm{~g}$ de cloreto de sódio p.a., previamente seco por 2 $\mathrm{h}$ a $150^{\circ} \mathrm{C}$, resfriado em dessecador, dissolvido com água deionizada e transferido para balão volumétrico de $1 \mathrm{~L}$.

Soluções padrão de $\mathrm{NaCl}$ foram preparadas para a determinação de sódio por fotometria de chama a partir de solução estoque de 1000 mg L ${ }^{-1} \mathrm{Na}$, preparada por dissolução a $1 \mathrm{~L}$ de $2,542 \mathrm{~g}$ do sal p.a. previamente seco. Curvas analíticas de calibração em 3 diferentes faixas de concentração de sódio (100 a 300, 10 a 75 e 1 a 5 mg L L $^{-1}$ ) foram usadas, incluindo em cada uma cinco pontos além do branco.

Inicialmente, o material biológico a ser preparado para teste da sua capacidade como dessalinizador foi lavado com água destilada para limpeza externa de sal e outras impurezas, seco à temperatura ambiente por aproximadamente $24 \mathrm{~h}$ e, então, triturado em um moinho de grãos (marca Bermar). Para sementes mais difíceis de moer, como as de umbu, essa etapa foi feita em moinho industrial, peneirando-se então o material por malha de $0,8 \mathrm{~mm}$.

\section{Extração do sal intrínseco ao material biológico}

Porções de $1 \mathrm{~g}$ do material biológico moído e seco foram pesadas e transferidas para béquers de $150 \mathrm{~mL}$, aos quais se adicionou $100 \mathrm{~mL}$ de água deionizada. Após vigorosa agitação com bastão de vidro, separou-se a solução por filtração a vácuo, determinando-se a concentração de sódio por fotometria de chama na solução filtrada. Este procedimento foi repetido até que não fosse mais detectado sódio naquela solução, procedendo-se então à secagem do material isento de sal e aos testes de sorção de sal da água salobra pelo material biológico.

\section{Testes de sorção de sal da água (salinidade $0,7 \%$ ) pelo material biológico}

Para a escolha da proporção adequada de material biológico/volume de água a ser dessalinizada em função da capacidade de sorção de sais pelo material, foram realizados testes fixando-se o volume de água salobra e o tempo de contato e variando-se a massa do material biológico. Alíquotas da solução foram então retiradas para análise, determinando-se a quantidade de sódio remanescente após o contato da água com o material em teste e, consequentemente, a capacidade de sorção de sal pelos diferentes materiais.

\section{Escolha do tempo de contato do material biológico com a água salobra}

Porções do material biológico previamente moído, lavado e seco à temperatura ambiente foram transferidas para 6 béqueres, ficando aí em contato com a água salobra por 10, 20, $30 \mathrm{~min}, 1,2$ e 3 h, na proporção $1 \mathrm{~g}: 100 \mathrm{~mL}$. Após o contato do material biológico com a água salobra procedeu-se à filtração a vácuo, retirando-se alíquotas da solução para determinação da concentração de sódio remanescente na água após sorção parcial do sal pelo material em teste. A percentagem de sorção de sal no material biológico foi calculada através da Equação 1:

$\%$ Sorção $=\left[\left([\mathrm{Na}]_{\text {inicial }}-[\mathrm{Na}]_{\text {Remanesc. }}\right) \times 100\right) /\left[\mathrm{Na}^{+}{ }_{\text {inicial }}\right]$ onde: $\left[\mathrm{Na}^{+}\right]_{\text {inicial }}$ representa a concentração inicial de sódio na água salobra antes do contato com o material biológico e $[\mathrm{Na}]_{\text {Remanesc., }}$, a concentração de sódio determinada na água após contato com o material biológico.

\section{Preparo do dispositivo caseiro para aplicação do material biológico dessalinizador}

Utilizou se no preparo do dispositivo dessalinizador um "filtro" de água caseiro, comercial (marca Sap Filtros), de plástico transparente, com capacidade de $4 \mathrm{~L}$, contendo uma vela oca de cerâmica adaptada como elemento filtrante.

Foram realizados dois procedimentos para dessalinização da água salobra usando-se a montagem acima referida, aplicando-se o material biológico tratado segundo os procedimentos descritos a seguir e água de baixa salobridade ( $\mathrm{S}=0,7 \%$ ), mantendo-se a proporção de $1 \mathrm{~g}: 100 \mathrm{~mL}$ (massa do material/volume da água salobra). Da água filtrada transferida através da vela filtrante para a parte inferior coletora foram recolhidas alíquotas para a determinação de sódio por fotometria de chama.

\section{Procedimento A}

Consistiu no enchimento da vela de cerâmica com o material biológico selecionado e adaptação ao "filtro" contendo a água salobra a ser filtrada em fluxo constante, através da vela "recheada". Um suporte de polipropileno com roscas de teflon foi utilizado para sustentar a mesma dentro do "filtro" (Figura 1S, material suplementar). A vela foi preenchida com o material biológico (sementes de umbu, previamente lavadas, trituradas e secas a $250^{\circ} \mathrm{C}$ ) e adaptada ao "filtro". A água salobra colocada no reservatório superior do "filtro" foi submetida ao processo de filtração usando-se dois tipos de velas de cerâmica encontradas comercialmente, com porosidades diferentes, o que produziu diferentes fluxos da água a ser filtrada.

\section{Procedimento $B$}

Consistiu na adaptação de um regulador de fluxo tipo equipo à vela oca de cerâmica, visando interromper o fluxo durante o processo de agitação da água com o material biológico na parte superior do filtro, feito com bastão de vidro, mantendo-se o contato por $10 \mathrm{~min}$ antes de permitir a filtração (Figura $2 \mathrm{~S}$, material suplementar).

\section{Aplicação do dispositivo dessalinizador a amostras reais de águas salobras}

Foram testadas 3 amostras reis de água salobra usadas por comunidades da Bacia do Rio Salitre, no semiárido baiano.

As amostras foram coletadas em frascos estéreis de polietileno de $1000 \mathrm{~mL}$ e foram armazenadas em geladeira até a realização dos testes com o dispositivo dessalinizador.

Antes e após o contato com o material biológico dessalinizador foram realizadas análises físico/químicas, tais como, $\mathrm{pH}$, condutividade elétrica (CE), sólidos totais dissolvidos (STD), sódio, potássio, cálcio e magnésio, visando avaliar parâmetros de qualidade daquelas águas mais associados aos sais possivelmente presentes nas mesmas. $\mathrm{O} \mathrm{pH}$ foi determinado potenciometricamente (pHmetro Denver, precisão de 0,02 unidades de $\mathrm{pH}$ ) usando-se um eletrodo de vidro combinado, calibrado com soluções de $\mathrm{pH}$ 4,0 e 7,0. Cálcio e magnésio foram determinados nas amostras de água salobra usando-se volumetria por complexação para a determinação da dureza. Potássio e sódio foram determinados por fotometria de chama. Para a medida da CE e dos STD usou-se um condutivímetro da marca Bunker, previamente calibrado com solução de $\mathrm{KCl}\left(146,9 \pm 0,5 \% \mu \mathrm{sm}^{-1}\right)$. 
Estudo do reaproveitamento do material biológico usado no dessalinizador após sua saturação com sais adsorvidos da água salobra

Os experimentos feitos para extração do sal do material biológico foram repetidos após seu uso como dessalinizador, até que não fosse mais detectada a presença de sódio no filtrado, medindo-se a quantidade de água necessária para isso, procedendo-se então à secagem (temperatura ambiente) do material isento de sal e seu reuso no dispositivo caseiro. Verificou-se então se a eficiência do material permanecia como no seu primeiro uso.

\section{Isotermas de adsorção}

Experimentos em batelada foram feitos a partir de $20 \mathrm{~mL}$ de soluções de concentrações de 170, 250, 300, 350, 400, 500 e 600 $\mathrm{mg} \mathrm{L}^{-1} \mathrm{Na}$ e $2 \mathrm{mg}$ do material biológico, sob agitação constante de $8 \mathrm{rpm}$, por um período de $10 \mathrm{~min}$. A influência da temperatura no processo de adsorção foi verificada a 30,40 e $50{ }^{\circ} \mathrm{C}$. Após o tempo de contato da solução com o material biológico e posterior filtração a vácuo, o sódio remanescente foi analisado na solução por fotometria de chama. A quantidade de sódio adsorvido por unidade de massa do adsorvente $\left(\mathrm{mg} \mathrm{g}^{-1}\right)$ foi calculada pela diferença entre a concentração no início do processo e após o equilíbrio da adsorção.

\section{RESULTADOS E DISCUSSÃO}

\section{Escolha do material biológico mais adequado para uso no dispositivo dessalinizador}

Os resultados do teor intrínseco de sódio nos diferentes materiais usados estão apresentados na Tabela 1, juntamente com os resultados dos testes para a sua extração, indicando o número de extrações necessárias para limpeza do material, o que foi feito com $1 \mathrm{~g}$ deste para $100 \mathrm{~mL}$ de água deionizada a cada extração.

Entre os materiais testados, a semente de girassol foi a única que não apresentou sal intrínseco. Nos casos das sementes de umbu $(0,010 \% \mathrm{Na})$ e de algaroba $(0,11 \% \mathrm{Na})$ o sal contido em $1 \mathrm{~g}$ do material foi extraído totalmente em uma única vez com $100 \mathrm{~mL}$ de água deionizada. Para isentar totalmente de sódio os outros materiais $(0,78$ a $1,71 \% \mathrm{Na})$ foram necessárias três extrações.
A Figura 1 mostra que entre os tipos de sementes estudadas, previamente moídas, lavadas e secas a $50{ }^{\circ} \mathrm{C}$ e colocadas em contato com água salobra por $1 \mathrm{~h}$, a semente de umburana - Amburana cearensis (Freire Allemão) A.C. Smithera foi o material biológico com maior capacidade de sorção de sais (22\%), seguida pelo umbu - Spondias tuberosa Arruda Câmara e mulungu - Erythrina verna Veloso (ambos $16 \%$ ). O mesmo não ocorreu quando o tempo de contato com a água salobra foi menor do que $10 \mathrm{~min}$. A umburana, por exemplo, absorveu nessas condições apenas $12 \%$ dos sais e os outros dois (umbu e mulungu) mantiveram os $16 \%$.

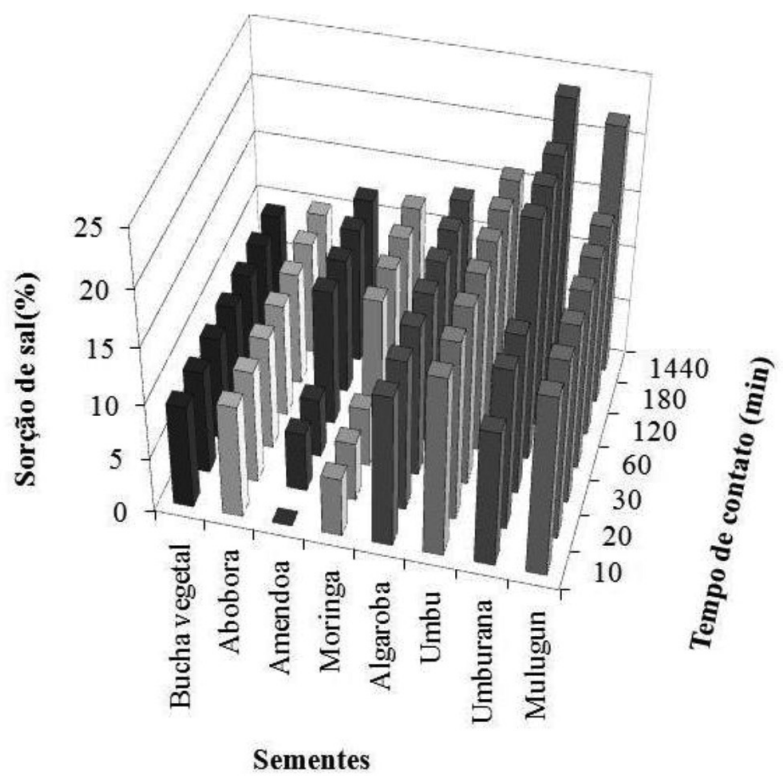

Figura 1. Percentagem de sorção de sal por diferentes tipos de sementes em função do tempo de contato com a água salobra. Condições: $1 \mathrm{~g}$ de material previamente moído, lavado e seco a $50^{\circ} \mathrm{C}$

A Tabela 2 apresenta resultados de testes de sorção de sais pelos materiais biológicos secos a diferentes temperaturas, durante tempos diferentes e deixados em contato com a água salobra por $10 \mathrm{~min}$. Observou-se que se mantendo a temperatura constante e variando-se o tempo de secagem, a eficiência de sorção de sais pelos diferentes

Tabela 1. Teor de sódio intrínseco ao material biológico e número de extrações necessárias para sua eliminação, considerando-se $1 \mathrm{~g}$ do material com $100 \mathrm{~mL}$ de água deionizada. Tempo de contato: $10 \mathrm{~min}$

\begin{tabular}{|c|c|c|c|c|c|}
\hline \multirow{3}{*}{ Material biológico } & \multicolumn{5}{|c|}{ № de extrações } \\
\hline & 1 & 2 & 3 & 4 & \multirow[t]{2}{*}{$\%$ Na intrínseco } \\
\hline & \multicolumn{4}{|c|}{$[\mathrm{Na}], \mathrm{mg} \mathrm{L}^{-1}$} & \\
\hline Mulungu, Erythrina verna Veloso & $15,1 \pm 0,10$ & $1,70 \pm 0,01$ & $0,310 \pm 0,01$ & 0,00 & 1,7 \\
\hline $\begin{array}{l}\text { Umburana, Amburana cearensis (Freire Allemão) A.C. } \\
\text { Smithera }\end{array}$ & $6,92 \pm 0,02$ & $2,61 \pm 0,01$ & 0,00 & - & 0,95 \\
\hline Moringa, Moringa oleifera Lam & $2,20 \pm 0,10$ & $1,03 \pm 0,05$ & $0,510 \pm 0,01$ & 0,00 & 0,37 \\
\hline Bucha vegetal, Luffa Cylindricall (L.) M. Roem & $0,810 \pm 0,01$ & $0,11 \pm 0,01$ & 0,00 & - & 0,092 \\
\hline Umbu, Spondias tuberosa Arruda Câmara & $0,100 \pm 0,02$ & 0,00 & - & - & 0,010 \\
\hline Algaroba, prosopis juliflora (SW.) D.C. & $1,11 \pm 0,02$ & 0,00 & - & - & 0,11 \\
\hline
\end{tabular}


Tabela 2. Percentagem de sorção de sal da água salobra por diferentes materiais biológicos previamente lavados e secos em diferentes temperaturas e tempos de secagem. Condições: $1 \mathrm{~g}$ de material; tempo de contato: $10 \mathrm{~min}$

\begin{tabular}{|c|c|c|c|c|c|c|c|}
\hline \multirow{2}{*}{$\begin{array}{c}\text { Material } \\
\text { biológico }\end{array}$} & \multirow{2}{*}{$\begin{array}{l}\text { Algaroba, } \\
\text { Prosopis juliflora } \\
\text { (SW.) D.C. }\end{array}$} & \multirow{2}{*}{$\begin{array}{l}\text { Mulungu, } \\
\text { Erythrina verna } \\
\text { Veloso }\end{array}$} & \multirow{2}{*}{$\begin{array}{c}\text { Umbu, } \\
\text { Spondias tuberosa } \\
\text { Arruda Câmara }\end{array}$} & \multirow{2}{*}{$\begin{array}{c}\text { Umburana, } \\
\text { Amburana cearensis } \\
\text { (Freire Allemão) A.C. } \\
\text { Smithera }\end{array}$} & \multicolumn{2}{|c|}{ Coco, Cocos Nucifera L. } & \multirow{2}{*}{$\begin{array}{l}\text { Girassol, } \\
\text { Helianthus } \\
\text { annus L. }\end{array}$} \\
\hline & & & & & Endocarpo & Mesocarpo & \\
\hline \multirow{2}{*}{$\begin{array}{c}\text { Tempo de } \\
\text { secagem (h) }\end{array}$} & \multicolumn{7}{|c|}{ Temperatura $\left({ }^{\circ} \mathrm{C}\right)$} \\
\hline & \multicolumn{7}{|c|}{50} \\
\hline 1 & $14 \pm 2$ & $16 \pm 4$ & $16 \pm 4$ & $22 \pm 3$ & $12 \pm 2$ & $13 \pm 1$ & - \\
\hline 2 & $14 \pm 2$ & $16 \pm 4$ & $16 \pm 4$ & $22 \pm 4$ & $12 \pm 3$ & $16 \pm 1$ & - \\
\hline 3 & $14 \pm 2$ & $16 \pm 4$ & $16 \pm 2$ & $22 \pm 3$ & $12 \pm 3$ & $16 \pm 2$ & - \\
\hline 4 & $14 \pm 2$ & $22 \pm 1$ & $16 \pm 2$ & $24 \pm 2$ & $12 \pm 2$ & $16 \pm 2$ & - \\
\hline 5 & - & - & - & - & $12 \pm 1$ & $16 \pm 1$ & - \\
\hline \multirow[t]{2}{*}{24} & - & - & - & - & $12 \pm 1$ & $16 \pm 1$ & - \\
\hline & \multicolumn{7}{|c|}{100} \\
\hline 1 & $14 \pm 2$ & $22 \pm 1$ & $14 \pm 4$ & $18 \pm 1$ & $12 \pm 1$ & $16 \pm 2$ & $3,6 \pm 2$ \\
\hline 2 & $19 \pm 1$ & $22 \pm 1$ & $14 \pm 4$ & $18 \pm 1$ & $16 \pm 1$ & $16 \pm 2$ & $3,6 \pm 2$ \\
\hline 3 & $19 \pm 1$ & $22 \pm 1$ & $14 \pm 4$ & $18 \pm 1$ & $16 \pm 1$ & $16 \pm 1$ & $3,6 \pm 1$ \\
\hline 4 & $19 \pm 4$ & $24 \pm 1$ & $16 \pm 1$ & $16 \pm 3$ & $16 \pm 1$ & $16 \pm 1$ & $3,6 \pm 1$ \\
\hline 5 & $19 \pm 4$ & $24 \pm 1$ & $16 \pm 1$ & $19 \pm 1$ & $16 \pm 1$ & $16 \pm 1$ & $3,6 \pm 1$ \\
\hline \multirow[t]{2}{*}{24} & $19 \pm 4$ & $24 \pm 1$ & $16 \pm 1$ & $19 \pm 1$ & $16 \pm 1$ & $16 \pm 1$ & $3,6 \pm 1$ \\
\hline & \multicolumn{7}{|c|}{150} \\
\hline 1 & $16 \pm 5$ & $22 \pm 2$ & $16 \pm 1$ & $18 \pm 1$ & $16 \pm 1$ & $16 \pm 2$ & $7,2 \pm 2$ \\
\hline 2 & $16 \pm 5$ & $22 \pm 2$ & $19 \pm 1$ & $18 \pm 1$ & $16 \pm 1$ & $16 \pm 2$ & $7,2 \pm 2$ \\
\hline 3 & $21 \pm 2$ & $22 \pm 2$ & $19 \pm 1$ & $18 \pm 1$ & $16 \pm 1$ & $16 \pm 1$ & $7,2 \pm 1$ \\
\hline 4 & $21 \pm 2$ & $24 \pm 1$ & $19 \pm 1$ & $19 \pm 1$ & $16 \pm 1$ & $16 \pm 1$ & $7,2 \pm 1$ \\
\hline 5 & $21 \pm 2$ & $24 \pm 1$ & $19 \pm 1$ & $19 \pm 1$ & $20 \pm 1$ & $16 \pm 1$ & $7,2 \pm 1$ \\
\hline \multirow[t]{2}{*}{24} & $21 \pm 2$ & $24 \pm 1$ & $19 \pm 1$ & $19 \pm 1$ & $20 \pm 1$ & $16 \pm 1$ & $7,2 \pm 1$ \\
\hline & \multicolumn{7}{|c|}{200} \\
\hline 1 & $20 \pm 1$ & $24 \pm 1$ & $20 \pm 1$ & $20 \pm 1$ & $16 \pm 2$ & $16 \pm 1$ & $11 \pm 3$ \\
\hline 2 & $13 \pm 4$ & $23 \pm 2$ & $21 \pm 2$ & $24 \pm 1$ & $16 \pm 2$ & $16 \pm 1$ & $11 \pm 3$ \\
\hline 3 & $13 \pm 4$ & $24 \pm 1$ & $21 \pm 3$ & $20 \pm 2$ & $16 \pm 2$ & $16 \pm 1$ & $11 \pm 2$ \\
\hline 4 & - & - & - & - & $16 \pm 2$ & $18 \pm 2$ & $11 \pm 1$ \\
\hline 5 & - & - & - & - & $21 \pm 1$ & $18 \pm 2$ & $11 \pm 1$ \\
\hline \multirow[t]{2}{*}{24} & - & - & - & - & $21 \pm 1$ & $18 \pm 2$ & $11 \pm 1$ \\
\hline & \multicolumn{7}{|c|}{250} \\
\hline 1 & $22 \pm 2$ & $20 \pm 3$ & $24 \pm 2$ & $25 \pm 1$ & - & $18 \pm 2$ & - \\
\hline 2 & - & - & - & - & - & $18 \pm 2$ & - \\
\hline 3 & - & - & - & - & - & $18 \pm 1$ & - \\
\hline 4 & - & - & - & - & - & $18 \pm 1$ & - \\
\hline 5 & - & - & - & - & - & $18 \pm 1$ & - \\
\hline 24 & - & - & - & - & - & $18 \pm 1$ & - \\
\hline
\end{tabular}

tipos de sementes praticamente se manteve constante a partir de $1 \mathrm{~h}$ de secagem. Desta forma, os testes de sorção de sal passaram a ser realizados com os materiais secos durante $1 \mathrm{~h}$, variando-se a temperatura de secagem, o que foi feito em $50,100,150,200$ e $250{ }^{\circ} \mathrm{C}$.

Os dados da Tabela 2 mostram também que houve um aumento na capacidade de sorção de sal por todos os materiais testados, destacando-se as sementes de umbu e umburana que absorveram, respectivamente, 16 e $12 \%$ de sal quando secas a $50{ }^{\circ} \mathrm{C}$ e passaram a absorver 24 e $25 \%$ quando secas a $250{ }^{\circ} \mathrm{C}$.

Entre todos os materiais biológicos testados a semente de umbu (Spondias tuberosa Arruda Câmara) foi considerada mais adequada ao uso no dispositivo dessalinizador, contendo muito baixo teor de sódio intrínseco $(0,010 \%)$ (Tabela 1$)$, facilitando sua purificação prévia, removendo da água salobra uma quantidade maior de sais do que os outros materiais quando pulverizada e seca a $250{ }^{\circ} \mathrm{C}$ e em contato com a água por 10 min (Tabela 2), podendo ainda ser encontrada facilmente em grandes quantidades na região semiárida baiana. A Figura 3S, material suplementar, apresenta uma montagem de fotos de um umbuzeiro e seus frutos, mostrando em detalhe a semente no seu interior.

\section{Resultados dos testes de dessalinização de água salobra com o dispositivo caseiro em duas montagens diferentes}

No Procedimento A, a vela com maior porosidade produziu um fluxo de $2 \mathrm{~mL} \mathrm{~s}^{-1}$ de água filtrada, enquanto que com a de menor 
porosidade o fluxo foi de $0,7 \mathrm{~mL} \mathrm{~s}^{-1}$. A percentagem de sorção de sais da água obtida com este procedimento se mostrou muito baixa (cerca de $8 \%$ ) quando comparada aos testes de bancada, cujos resultados foram apresentados anteriormente, indicando que não estava ocorrendo contato adequado entre a água e o material biológico contido dentro da vela. Já no Procedimento B, a eficiência do processo de adsorção de sais foi maior, determinada testando-se sem agitação do material na água, com pouca agitação e com vigorosa agitação, obtendo-se respectivamente $20 \pm 2,23 \pm 2$ e $24 \pm 1 \%$ de sorção de sal pelo material usado como dessalinizador.

\section{Aplicação do dispositivo caseiro a amostras reais de água salobra}

Foram usadas no dispositivo desenvolvido águas salobras reais com salinidade desde 0,6 a 1,2\%o, incluindo águas consideradas muito duras (dureza como $\mathrm{CaCO}_{3}>200 \mathrm{mg} \mathrm{L}^{-1}$ ). ${ }^{12}$ Características químicas importantes com relação à qualidade daquelas águas foram determinadas antes do uso no dispositivo dessalinizador e estão apresentadas na Tabela 3.
Usando o Procedimento B foram realizados também testes com água salobra real e sementes tratadas de mulungu e umburana, já que as mesmas apresentaram capacidade de sorção de 20 e $25 \%$ (Tabela 2), respectivamente, próximas àquela conseguida com as sementes de umbu (24\%), quando secas a $250{ }^{\circ} \mathrm{C}$. Na Tabela 3 estão apresentados também os parâmetros de qualidade das águas, determinados após aplicação da água ao dispositivo. Foi também mantida a proporcionalidade entre massa do material biológico e volume de água usada nos testes da capacidade de adsorção dos materiais. Assim, no "filtro" comercial (capacidade de $4 \mathrm{~L}$ ) foram usadas $40 \mathrm{~g}$ do material biológico.

Os dados apresentados da Tabela 3 mostram que se usando sementes de umbu, como material dessalinizador, houve uma redução média na concentração de STD das águas salobras de $33 \pm 6 \%$. Isso não foi suficiente para tornar a amostra 3 uma água doce (STD $<500$ mg L ${ }^{-1}$ ), de acordo com a Resolução CONAMA 357/05, ${ }^{13}$ embora a coloque em condições de potabilidade com relação a este parâmetro de qualidade de água, segundo a portaria 518/2004 do Ministério da Saúde, ${ }^{14}$ a qual admite até $1000 \mathrm{mg} \mathrm{L}^{-1}$ STD.

O comportamento do material produzido com as sementes de mu-

Tabela 3. Parâmetros de qualidade de águas salobras do semiárido baiano antes e após contato com o material biológico por 10 min, previamente livre de sal e seco a $250{ }^{\circ} \mathrm{C}$ por $1 \mathrm{~h}$

\begin{tabular}{|c|c|c|c|c|c|c|c|c|c|c|}
\hline \multirow{3}{*}{$\begin{array}{l}\text { Característi- } \\
\text { cas da água } \\
\text { salobra }\end{array}$} & \multicolumn{10}{|c|}{ Parâmetros de qualidade da água } \\
\hline & \multirow[t]{2}{*}{ Água salobra } & \multirow{2}{*}{$\begin{array}{c}\mathrm{CE}^{*} \\
\left(\mu \mathrm{S} \mathrm{cm}^{-1}\right)\end{array}$} & \multirow[t]{2}{*}{$\mathrm{pH}$} & \multirow[t]{2}{*}{ S \%o } & $\mathrm{Na}$ & K & STD ** & $\mathrm{Ca}$ & $\mathrm{Mg}$ & $\begin{array}{c}\text { Dureza } \\
\left(\mathrm{CaCO}_{3}\right)\end{array}$ \\
\hline & & & & & \multicolumn{6}{|c|}{$\left(\mathrm{mg} \mathrm{L}^{-1}\right)$} \\
\hline \multirow{3}{*}{$\begin{array}{l}\text { Antes do } \\
\text { contato com } \\
\text { o material } \\
\text { biológico }\end{array}$} & 1 & 1690 & 7,25 & 0,78 & 245 & 2,3 & 779 & $117 \pm 0,8$ & $61,7 \pm 0,4$ & $546 \pm 4$ \\
\hline & 2 & 1321 & 7,71 & 0,62 & 159 & 1,5 & 619 & $157 \pm 0,4$ & $69,4 \pm 0,2$ & $616 \pm 2$ \\
\hline & 3 & 2280 & 7,89 & 1,2 & 267 & 4,3 & 1218 & $113 \pm 1,2$ & $84,2 \pm 0,4$ & $628 \pm 4$ \\
\hline \multirow{15}{*}{$\begin{array}{l}\text { Após o } \\
\text { contato com } \\
\text { o material } \\
\text { biológico }\end{array}$} & \multicolumn{10}{|c|}{ Umbu, Spondias tuberosa Arruda Câmara } \\
\hline & 1 & $1132(\mathbf{3 3} \%)$ & 6,02 (17\%) & $0,51(\mathbf{3 5 \%})$ & $136(44 \%)$ & $2,0(\mathbf{1 5 \%})$ & $514(34 \%)$ & $\begin{array}{c}78,1 \pm 0,4 \\
(\mathbf{3 3 \%})\end{array}$ & $\begin{array}{c}44,4 \pm 0,2 \\
(\mathbf{2 8 \%})\end{array}$ & $377 \pm 2(31 \%)$ \\
\hline & 2 & $953(\mathbf{2 8 \%})$ & 6,94 (10\%) & $0,45(\mathbf{2 7 \%})$ & $74(\mathbf{5 3 \%})$ & $1,0(\mathbf{3 3 \%})$ & $454(27 \%)$ & $\begin{array}{c}77,2 \pm 0,4 \\
(\mathbf{5 1 \%})\end{array}$ & $\begin{array}{c}54,4 \pm 0,2 \\
(\mathbf{2 2 \%})\end{array}$ & $\begin{array}{c}389 \pm 3 \\
(37 \%)\end{array}$ \\
\hline & 3 & $1396(\mathbf{3 9 \%})$ & $7,42(6 \%)$ & $0,76(37 \%)$ & $160(40 \%)$ & $3,0(\mathbf{3 0 \%})$ & $759(\mathbf{3 8 \%})$ & $\begin{array}{c}84,0 \pm 0,4 \\
(\mathbf{2 6 \%})\end{array}$ & $\begin{array}{c}73,1 \pm 0,2 \\
(\mathbf{1 3 \%})\end{array}$ & $\begin{array}{c}511 \pm 2 \\
(\mathbf{1 7 \%})\end{array}$ \\
\hline & Média \% & $33 \pm 5$ & $11 \pm 6$ & $33 \pm 5$ & $46 \pm 7$ & $25 \pm 11$ & $33 \pm 6$ & $37 \pm 13$ & $21 \pm 7$ & $28 \pm 10$ \\
\hline & \multicolumn{10}{|c|}{ Mulungu, Erythrina verna Veloso } \\
\hline & 1 & $1830(+\mathbf{8 \%})$ & $7,61(+5 \%)$ & $0,75(4 \%)$ & $181(\mathbf{2 6 \%})$ & $2,0(\mathbf{1 3 \%})$ & $757(3 \%)$ & $\begin{array}{c}154 \pm 1,2 \\
(+\mathbf{3 2} \%)\end{array}$ & $\begin{array}{c}64,1 \pm 0,4 \\
(+4 \%)\end{array}$ & $\begin{array}{l}648 \pm 5 \\
(+19 \%)\end{array}$ \\
\hline & 2 & $1398(+6 \%)$ & 7,93 (+3\%) & $0,60(3 \%)$ & $133(\mathbf{1 7 \%})$ & $1,0(33 \%)$ & $601(3 \%)$ & $\begin{array}{c}210 \pm 0,4 \\
(+\mathbf{3 4 \%})\end{array}$ & $\begin{array}{c}97,2 \pm 0,2 \\
(+\mathbf{4 0 \%})\end{array}$ & $\begin{array}{l}926 \pm 2 \\
(+\mathbf{5 0 \%})\end{array}$ \\
\hline & 3 & $2469(+8 \%)$ & $7,82(+7 \%)$ & $1,2(\mathbf{0 \%})$ & $181(32 \%)$ & 4,0 (7\%) & $1184(3 \%)$ & $\begin{array}{c}132 \pm 0.4 \\
(+\mathbf{1 7 \%})\end{array}$ & $\begin{array}{c}155 \pm 0,4 \\
(+\mathbf{8 3} \%)\end{array}$ & $\begin{array}{l}967 \pm 3 \\
(+\mathbf{5 4 \%})\end{array}$ \\
\hline & Média \% & $+7 \pm 1$ & $+7 \pm 3$ & $2 \pm 2$ & $25 \pm 7$ & $18 \pm 4$ & $3 \pm 0$ & $+27 \pm 4$ & $+43 \pm 40$ & $+41 \pm 19$ \\
\hline & \multicolumn{10}{|c|}{ Umburana, Amburana cearensis (Freire Allemão) A.C. Smithera } \\
\hline & 1 & $1820(+\mathbf{8 \%})$ & 6,41 (12\%) & $0,95(+\mathbf{2 0} \%)$ & $211(\mathbf{1 4 \%})$ & $2,0(\mathbf{1 3 \%})$ & $955(+23 \%)$ & $\begin{array}{c}128 \pm 0,4 \\
(+9 \%)\end{array}$ & $\begin{array}{c}80,2 \pm 0,2 \\
(+\mathbf{3 0 \%})\end{array}$ & $\begin{array}{l}649 \pm 2 \\
(+19 \%)\end{array}$ \\
\hline & 2 & $1658(+26 \%)$ & 6,80 (12\%) & $0,86(+39 \%)$ & $141(\mathbf{1 1 \%})$ & $1,0(\mathbf{3 3 \%})$ & $861(+39 \%)$ & $\begin{array}{c}169 \pm 0,4 \\
(+8 \%)\end{array}$ & $\begin{array}{c}72,7 \pm 0,2 \\
(+5 \%)\end{array}$ & $\begin{array}{l}721 \pm 2 \\
(+\mathbf{1 7 \%})\end{array}$ \\
\hline & 3 & $1525(33 \%)$ & 6,63 (16\%) & 1,2 (0\%) & $177(34 \%)$ & $4,0(\mathbf{7 \%})$ & $1239(+\mathbf{2 \%})$ & $\begin{array}{c}108 \pm 0,4 \\
(\mathbf{4 \%})\end{array}$ & $\begin{array}{c}88,7 \pm 0,2 \\
(+\mathbf{5 \%})\end{array}$ & $\begin{array}{c}635 \pm 2 \\
(+1 \%)\end{array}$ \\
\hline & Média \% & $8 \pm 30$ & $13 \pm 2$ & $+20 \pm 19$ & $20 \pm 12$ & $18 \pm 10$ & $+21 \pm 19$ & $+4 \pm 8$ & $+13 \pm 14$ & $+12 \pm 10$ \\
\hline
\end{tabular}

Entre parênteses e médias: alteração percentual do parâmetro de qualidade da água salobra colocada em contato com o material biológico. Sinais positivos indicam transferência de espécies químicas do material para a água, piorando a qualidade da mesma em relação àquele parâmetro. * CE $=$ Condutividade Elétrica ; ** STD = Sólidos Totais Dissolvidos 
lungu e de umburana em contato com águas salobras reais no dispositivo dessalinizador não foi o esperado, uma vez que nos testes com a solução de $\mathrm{NaCl}$ simulando a água salobra, a concentração de sódio na água era reduzida após contato com estes materiais. No entanto, os resultados apresentados na Tabela 3, decorrentes da aplicação de amostras reais de água salobra, apresentam para esses materiais acréscimos na condutividade elétrica, redução muito pequena ou aumento nas concentrações de STD, de cálcio e de magnésio, aumentando consequentemente a salinidade das águas, além de apresentarem percentuais de redução da concentração de sódio bem mais baixos. Esses materiais (mulungu e umburana) devem conter originalmente um certo teor de $\mathrm{Ca}$ e $\mathrm{Mg}$ que além de não ser removido no tratamento prévio do material, como ocorreu com o sódio, é transferido para a água quando aplicada ao dispositivo que pretendia dessalinizá-la.

\section{Estudo do reuso do material biológico preparado com sementes de umbu}

Considerando-se a quantidade de água necessária para retirar o sal adsorvido no material dessalinizador e o baixo custo desse material, entende-se que o custo/beneficio do seu reuso seja alto. Além disso, a eficiência do processo de dessalinização reduz significativamente após o primeiro uso: na prática, a salinidade da água baixou apenas cerca de $6 \%$ e a dureza de $13 \%$, contra 35 e $31 \%$, respectivamente, no primeiro uso do material.

\section{O processo de adsorção de sais pelo material biológico preparado com sementes de umbu}

A Figura 2 mostra isotermas de adsorção para o sistema monocomponente sódio em umbu ajustadas para o modelo de Langmuir. ${ }^{15-17}$ Ela representa a acumulação de sódio na superfície do material biológico preparado com sementes de umbu, expressando a quantidade adsorvida por quantidade de adsorvente $(\mathrm{X} / \mathrm{m})$ em função da concentração do adsorvato $(\mathrm{Ce})$ em solução, resultando nas isotermas de adsorção. ${ }^{18,19}$ A Figura 2 permite observar um aumento considerável da capacidade de adsorção com o aumento da temperatura. Através da mesma foi possível estimar a capacidade máxima de adsorção de sódio pelo material biológico em questão a 30,40 e $50{ }^{\circ} \mathrm{C}$ em 52,6, 165 e $250 \mathrm{mg} \mathrm{g}^{-1}$, respectivamente. Desta forma, de acordo com aquele modelo, aquecendo-se a água a $50{ }^{\circ} \mathrm{C}$ é possível remover todo o sódio contido em $1 \mathrm{~L}$ daquelas águas salobras do semiárido baiano, as quais continham, respectivamente, 245,159 e $267 \mathrm{mg} \mathrm{L}^{-1}$ $\mathrm{Na}$, usando-se apenas cerca de $1 \mathrm{~g}$ de sementes de umbu tratadas segundo indicado neste trabalho.

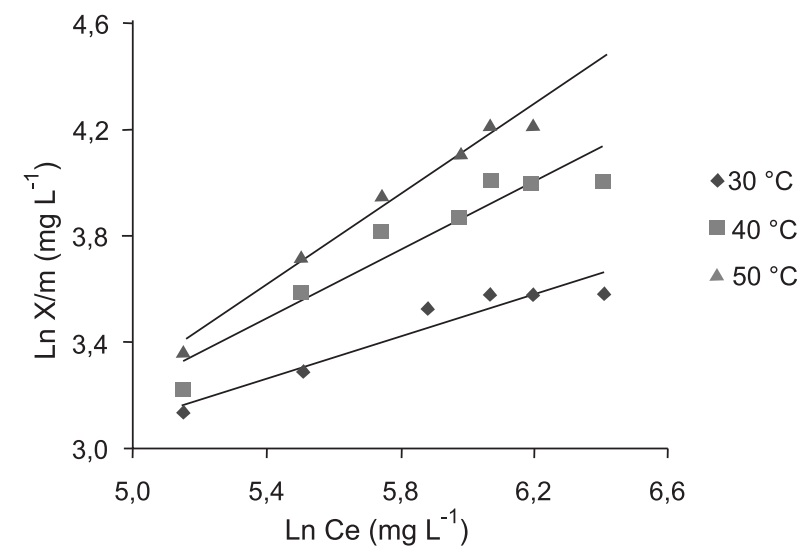

Figura 2. Isotermas de adsorção ajustadas ao modelo de Langmuir. $\left(C_{0}=\right.$ $170 \mathrm{mg} \mathrm{L}^{-1}$; agitação $8 \mathrm{rpm}$ )
Com base nos dados obtidos pelo modelo de Langmuir e considerando-se a concentração de $\mathrm{NaCl}$ em águas de diferentes salinidades, foram construídas curvas em função da massa de umbu requerida para remoção de todo o $\mathrm{NaCl}$ das águas nas temperaturas de 30,40 e $50{ }^{\circ} \mathrm{C}$ (Figura 3). A massa de sementes de umbu seca necessária para remoção do sal em cada litro de água, em diferentes temperaturas, também pode ser estimada pelas equações dessas curvas, determinando o uso deste processo de dessalinização ${ }^{20} \mathrm{com}$ maior eficiência. Menezes et al. ${ }^{21}$ apresentam em detalhes o estudo do referido processo de adsorção de sódio por sementes de umbu.

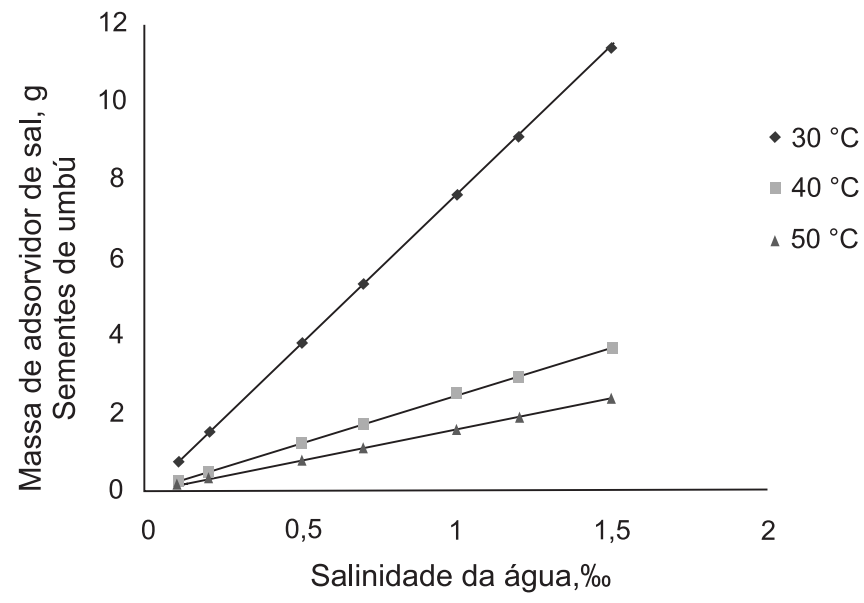

Figura 3. Massa do umbu requerida para remoção de sal por litro de água salobra em função da salinidade e diferentes temperaturas: 30,40 e $50{ }^{\circ} \mathrm{C}$. Equações das curvas: $Y_{\left(300^{\circ} \mathrm{C}\right)}=7,575 \mathrm{X} ; Y_{\left(400^{\circ} \mathrm{C}\right)}=2,457 \mathrm{X} ; Y_{\left(500^{\circ} \mathrm{C}\right)}=1,592 \mathrm{X}$

\section{CONCLUSÕES}

A semente de umbu (Spondias tuberosa Arruda Câmara) apresentou características mais adequadas para ser usada como material dessalinizador de água salobra: maior capacidade de adsorção de sais da água, principalmente quando seca a $250^{\circ} \mathrm{C}$ por $1 \mathrm{~h}$, menor teor original de sais, facilitando sua purificação prévia e podendo ser encontrada facilmente em grandes quantidades na região semiárida baiana.

O dispositivo caseiro desenvolvido para dessalinização de água salobra, em pequenas quantidades, suficientes para uso familiar em dessedentação humana a partir de sementes de umbu tratadas segundo indicação neste trabalho, pode transformar água de baixa salobridade, mas imprópria para beber ( $>0,5$ a $1,5 \%$ ) em água doce e alterar a característica de águas altamente duras para águas com padrões de aceitação de consumo humano.

O estudo da adsorção dos sais no material preparado, realizado para explicar o processo de dessalinização da água salobra, atende ao modelo de Langmuir.

A capacidade máxima estimada para a adsorção de sódio pelo material preparado com sementes de umbu permitiu concluir que 1 L de água salobra, como aquelas do semiárido baiano testadas, pode ter seu teor de sal referente a cloreto de sódio removido com apenas $1 \mathrm{~g}$ do material, se a água for aquecida a $50{ }^{\circ} \mathrm{C}$.

\section{MATERIAL SUPLEMENTAR}

Figuras com fotos do procedimento A para montagem do dispositivo dessalinizador (Figura 1S) e do procedimento B (Figura 2S) e uma figura composta por fotos de um umbuzeiro e seus frutos, mostrando a semente no seu interior (Figura 3S) são apresentadas como material suplementar, disponível em http://quimicanova.sbq. org.br, na forma de arquivo pdf com acesso livre. 


\section{AGRADECIMENTOS}

Ao apoio financeiro da Capes pela bolsa concedida e ao CNPQ pelo financiamento do projeto.

\section{REFERÊNCIAS}

1. Grassi, M. T.; Cadernos Temáticos de Química Nova na Escola, Maio, 2001.

2. Rebouças, A. C.; Estudos Avançados 2001, 15, 327.

3. Suassuna, J.; Parcerias Estratégicas 2005, 20, 119, em Seminários temáticos para a $3^{a}$ Conferência Nacional de $C, T \& I$.

4. http://www.ana.gov.br/SalaImprensa/anexos/not230-anexo1.pdf, acessada em Agosto 2011

5. Rebouças, A. C.; Estudos Avançados 1997, 11, 29.

6. Costa, A. M. B.; Melo, J. G.; Silva, F. M.; Águas Subterrâneas 2006, 20, 67.

7. Silva Jr, L. G. A.; Gheyi, H. J.; Medeiros, J. F.; Rev. Bras. Eng. Agríc. Ambient. 1999, 3, 11.

8. Soares, T. M.; Silva, I. J. O.; Duarte, S. N.; Silva, E. F. F.; Rev. Bras. Eng. Agríc. Ambient. 2006, 10, 730 .

9. Porto, E. R.; Amorim, M. C. C. de; Silva Júnior, L. G. A.; Rev. Bras. Eng. Agríc. Ambient. 2001, 5, 111.
10. Pessoa, L. C. C.; Dissertação de Mestrado, Universidade Federal do Ceará, Brasil, 2000.

11. Oliveira, C. N.; Campos,V. P.; Medeiros, Y. D. P.; Quim. Nova 2010, 33, 1059.

12. Rebouças, A. C.; Braga, B.; Tundisi, J. G.; Águas Doces no Brasil Capital Ecológico, Uso e Conservação, $3^{\mathrm{a}}$ ed., Escrituras: São Paulo, 2006.

13. http://www.cetesb.sp.gov.br/Agua/praias/res_conama_357_05.pdf, acessada em Agosto 2011.

14. http://portal.saude.gov.br/portal/arquivos/pdf/portaria_518.pdf, acessada em Agosto 2011.

15. Sales, J. A. A.; Airoldi, C.; Thermochim. Acta 2005, 427, 77.

16. Pereira, P. H. F.; Silva, M. L. P.; Quim. Nova 2009, 32, 7.

17. Araujo, A. L. P.; Silva, M. C. C.; Gimenes, M. L.; Barros, M. A. S. D.; Scientia Plena 2009, 1.

18. Oscik, J.; Cooper, I. L.; Adsorption, John Wiley \& Sons: New York, 1982.

19. Perry, J.; Manual del Ingeneiro Químico, $6^{\text {th }}$ ed., Mc Graw: Barcelona, 1998.

20. Campos, V. P.; Menezes, J. S.; Protocolo INPI número 011100001118 , Patente depositada em 23/12/2010.

21. Menezes, S. J.; Campos,V. P. ; Costa, T. A. C.; Desalination (2011) doi: 10.1016/j.desal.2011.08.002 